\title{
Preventive efficacy of oral moxidectin at various doses and dosage regimens against macrocyclic lactone-resistant heartworm (Dirofilaria immitis) strains in dogs
}

Tom L. McTier*, Robert H. Six, Aleah Pullins, Sara Chapin, Kristina Kryda, Sean P. Mahabir, Debra J. Woods and Steven J. Maeder

\begin{abstract}
Background: Moxidectin has previously shown limited efficacy $(\leq 44.4 \%)$ against confirmed macrocyclic lactone (ML)-resistant Dirofilaria immitis strains at $3 \mu \mathrm{g} / \mathrm{kg}$ after single and multiple oral dosages. Three studies were conducted to evaluate higher oral moxidectin doses for efficacy against confirmed ML-resistant D. immitis strains.

Methods: Dogs were inoculated with 50 D. immitis $L 3$ and randomly allocated to treatments. Study 1: 6 groups of dogs $(n=8)$ were inoculated with JYD-34 (Day - 30) and treated as follows: T01, negative control; T02-T05, moxidectin at 3,6, 12 or $24 \mu \mathrm{g} / \mathrm{kg}$, respectively, on Day 0 only; T06, moxidectin at $3 \mu \mathrm{g} / \mathrm{kg}$ on Days 0,30 and 60. Study 2: 10 groups of dogs $(n=5)$ were inoculated (Day -30$)$ with either JYD-34 (T01,T03-05) or ZoeLA (T02, T06-T10) and treated as follows: T01 and T02, negative controls; T03-T05, moxidectin at 24, $40 \mathrm{or} 60 \mathrm{\mu g} / \mathrm{kg}$, respectively, on Days 0, 28 and 56; T06 and T09, moxidectin at 3 or $60 \mu \mathrm{g} / \mathrm{kg}$ on Day 0 only; T07, T08 and T10, moxidectin at 24, 40 or $60 \mu \mathrm{g} /$ $\mathrm{kg}$, respectively, on Days 0, 28 and 56. Study 3: 5 groups of dogs $(n=5)$ were inoculated with ZoeMO (Day -28$)$ and treated as follows: T01, negative control; T02, moxidectin at $3 \mu \mathrm{g} / \mathrm{kg}$ moxidectin on Day 0 only; T03-T05, moxidectin at 24,40 or $60 \mu \mathrm{g} / \mathrm{kg}$, respectively, on Days 0, 28 and 56 . All dogs were necropsied for adult heartworm recovery $\sim 4-5$ months post-inoculation.

Results: All moxidectin-treated dogs showed significantly lower worm counts than controls. The efficacy of moxidectin administered once at $3 \mu \mathrm{g} / \mathrm{kg}$ was 19\% (JYD-34), 44.4\% (ZoeLA) and 82.1\% (ZoeMO). Increasing both the dose and the number of dosages of moxidectin improved efficacy, with 100\% protection obtained using three dosages of moxidectin at either $40 \mu \mathrm{g} / \mathrm{kg}$ (JYD-34, ZoeMO) or $60 \mu \mathrm{g} / \mathrm{kg}$ (ZoeLA). Three dosages of $24 \mu \mathrm{g} / \mathrm{kg}$ were also highly effective, providing $\geq 98.8 \%$ efficacy for all three strains.

Conclusions: Increasing both the dose and number of consecutive monthly dosages of moxidectin improved the efficacy against ML-resistant heartworms. Based on these data and other technical considerations, the $24 \mathrm{\mu g} / \mathrm{kg}$ dose was considered the optimal dose for further commercial development.
\end{abstract}

Keywords: Dirofilaria immitis, Heartworm, Canine, Macrocyclic lactone, Resistance, Moxidectin 


\section{Background}

Macrocyclic lactones (MLs) have been used to effectively and safely protect dogs against heartworm (HW) disease for more than 30 years [1-11], with ivermectin (Heartgard ${ }^{\circledR}$, Merial, Duluth, GA, USA), selamectin (Revolution ${ }^{\circledR} /$ Stronghold $^{\circledR}$, Zoetis, Parsippany, NJ, USA), moxidectin (ProHeart ${ }^{\circledR}$ 6/SR-12, Zoetis, Parsippany; Advantage Multi ${ }^{\circledR}$, Bayer Animal Health, Shawnee, KS, USA) and milbemycin oxime (Interceptor ${ }^{\circledR}$, Elanco, Greenfield, IN, USA) historically providing $100 \%$ efficacy against Dirofilaria immitis when used as recommended. However, canine HW disease incidence continues to increase in many countries around the world including the USA [12-16]. The Companion Animal Parasite Council reported a $15.3 \%$ increase in cases of dogs positive for D. immitis between 2013 and 2016 [17], and the American Heartworm Society (AHS) reported an increase of $21.7 \%$ in the average number of cases per clinic over the same time period $[16,18]$. This rise in incidence is concerning but not necessarily surprising given that it is likely that less than $35 \%$ of the 70 million pet dogs in the USA are regularly tested for $D$. immitis infection and up to $70 \%$ do not receive a regular HW preventive [13].

Reports of ML lack of efficacy (LOE) in the field have increased in the last ten years [19-24] and the lack of regular and correct administration of available preventives is a major contributor to this problem [13, 16, 19, 24]. In their analysis of $271 \mathrm{LOE}$ reports from the USA involving dogs on HW prevention, Atkins et al. [19] found insufficient preventive was purchased by owners to provide AHS-recommended year-round protection in more than $80 \%$ of the cases. The emergence of $D$. immitis populations resistant to ML treatment has added a new dimension to this already complex problem. At present, efficacy data collected in both the laboratory and field confirm ML resistance is a growing problem [25-33], and analyses conducted on various $D$. immitis isolates/strains have confirmed genetic differences that are associated with the resistance phenotype [20, 27, 34-37]. The confirmation of ML resistance in these strains, in conjunction with the possibility of as yet unidentified strains circulating in the field, raises concerns for the future viability of present canine HW disease prevention methods and underscores the need to define the extent of ML resistance in D. immitis and develop new approaches to prevention.

Moxidectin is a ML presently available in HW preventive products worldwide that has a proven track record of preventing HW disease $[2,3,5,7,8,38]$. Within the USA, moxidectin is marketed in two presentations, topical (Advantage Multi ${ }^{\circledR}$ and Coraxis ${ }^{\mathrm{TM}}$, Bayer Animal Health) and injectable (ProHeart ${ }^{\circledR} 6$ and ProHeart ${ }^{\circledR} 12$, Zoetis, Parsippany). Moxidectin was also previously approved as an oral formulation and is still marketed as such outside the USA (e.g. ProHeart ${ }^{\circledR}$ tablets, Zoetis, Parsippany). All four formulations provided $100 \%$ protection against ML-susceptible $D$. immitis strains with a single dose on original approval and in subsequent laboratory studies [1-3, 5, 7, 8, 32, 38]. Moxidectin has also been shown to have activity against a number of ML-resistant D. immitis strains in all three formulations and it often performs equally well or better than other MLs against ML-resistant strains [39]. For example, the JYD-34 $D$. immitis strain has been confirmed genetically and in laboratory efficacy studies to be highly ML-resistant, but one administration of Advantage Multi ${ }^{\circledR}$ provided dogs with $100 \%$ protection against the strain [25] and a single ProHeart ${ }^{\circledR} 6$ injection provided $99.5 \%$ efficacy [29]. Additionally, three monthly dosages of oral moxidectin at the minimum recommended label dose $(3 \mu \mathrm{g} / \mathrm{kg})$ were $44.4 \%$ effective against JYD-34 [32], which is higher than the efficacy obtained with three dosages of either ivermectin $(6 \mu \mathrm{g} / \mathrm{kg})\left(29.0 \%\right.$, as Heartgard ${ }^{\circledR}$ Plus) or selamectin (6 $\mathrm{mg} / \mathrm{kg})\left(28.8 \%\right.$, as Revolution $\left.{ }^{\circledR}\right)$ and similar to the protection provided by three dosages of milbemycin oxime ( 0.5 $\mathrm{mg} / \mathrm{kg})\left(52.2 \%\right.$, as Trifexis ${ }^{\circledR}$, Elanco, Greenfield, IN, USA) [25]. In addition to JYD-34, a single dose of oral moxidectin $(3 \mu \mathrm{g} / \mathrm{kg})$ has shown efficacy against the resistant ZoeLA, AMAL and ZoeMO D. immitis strains, providing dogs with $54.0 \%, 61.6 \%$ and $82.7 \%$ preventive efficacy, respectively [32]. Recent work has also highlighted the microfilaricidal activity of moxidectin against the ZoeMO D. immitis strain, with more than 95\% reduction in circulating microfilariae reported for infected dogs within 12 weeks of treatment with ProHeart ${ }^{\circledR} 6$ or ProHeart ${ }^{\circledR} 12$ compared to control dogs [31]. Finally, recent data from a large field study of client-owned dogs demonstrated that ProHeart ${ }^{\circledR} 12$ was $100 \%$ effective in preventing HW disease for 12 months in 236 dogs, of which $52(22 \%)$ were recruited from the lower Mississippi River valley (LMRV), where ML resistance has been confirmed to occur [23]. In the same study, there were four dogs (4 of 218) in the positive control group, Heartgard ${ }^{\circledR}$ Plus, that developed heartworm infections, with all four cases coming from the LMRV, suggesting the reason for the preventive failures may have been due to exposure to ML-resistant HWs.

However, in spite of the encouraging activity of moxidectin in topical and injectable formulations, as with other MLs, the dosages tested to date for oral moxidectin have provided incomplete protection in dogs against ML-resistant $D$. immitis strains. The aim of the three studies reported here was to investigate whether increasing the oral moxidectin dose and increasing the number of consecutive monthly treatments would improve efficacy against ML-resistant $D$. immitis strains. 


\section{Methods}

\section{Study guidelines}

Studies were conducted in accordance with the Center for Veterinary Medicine (CVM) Guidance for Industry \#90, Effectiveness of Anthelmintics: General Recommendations (VICH guideline GL7) [40] and CVM Guidance for Industry \#113, Efficacy of Anthelmintics-Specific Recommendations for Canines (VICH guideline GL19) [41].

\section{Study design}

Three masked, negative, placebo-controlled, randomized studies were designed to evaluate the efficacy of different doses and dosage regimens of oral moxidectin in preventing $\mathrm{HW}$ disease against three ML-resistant $D$. immitis strains, namely JYD-34, ZoeMO and ZoeLA in dogs.

\section{Study 1}

A total of 48 dogs (24 female, 24 male) were inoculated with 50 D. immitis JYD-34 third-stage larvae (L3) on Day -30 . Dogs were allocated to treatment groups and pens following a randomized block design, with block based on Day -8 body weight and pen location. Dogs were treated with either placebo [an empty hydroxypropyl methycellulose (HPMC) capsule] (T01) or HPMC capsules filled with the appropriate amount of hand-pulverized ProHeart ${ }^{\circledR}$ tablets to deliver a dose of 3, 6, 12 or 24 $\mu \mathrm{g} / \mathrm{kg}$ moxidectin on Day 0 only (T02-T05) or on Days 0 , 30 and 60 (Groups T01 and T06) (Table 1). All dogs were necropsied for recovery and enumeration of adult HWs on Day 122 (152 days post-inoculation). The results generated as part of this study for the $3 \mu \mathrm{g} / \mathrm{kg}$ groups (T02 and T06) and the placebo group (T01) have been previously published [32] but are being reported again here for completeness and to provide background for the rationale of the study design.

\section{Study 2}

Fifty dogs (25 female, 25 male) were allocated to treatment following a randomized block design within room, with block based on pen location within room and Day -35 body weight. Ten groups $(n=5)$ of dogs were inoculated with 50 D. immitis L3 on Day -30 ; four groups (T01, T03-T05) were given the JYD-34 strain and six groups (T02, T06-T10) were given the ZoeLA strain. On Day -3 , dogs were moved to their allocated treatment pens. Treatment consisted of either a placebo (a tablet containing inert ingredients) or oral moxidectin (ProHeart ${ }^{\circledR}$ tablets shaved to deliver the correct dose). Placebo tablets were administered on Days 0, 28 and 56 (T01, T02). Moxidectin was administered at 3 (T06), 24 (T03, T07), 40 (T04, T08) or $60 \mu \mathrm{g} / \mathrm{kg}$ (T05, T09, T10), and treatments were given either on Day 0 only (T06 and T09) or on Days 0, 28 and 56 (T03, T04, T05, T07, T08, T10) (Table 2). Efficacy of moxidectin in preventing HW infection was evaluated at Day 103 (133 days post-inoculation) following necropsy and adult worm recovery and enumeration.

\section{Study 3}

Twenty-five dogs (15 female, 10 male) were allocated to five treatment groups $(n=5)$ and pens according to a randomized block design. Block was based on pen location and Day -34 body weights. All animals were inoculated with 50 D. immitis L3 on Day - 28 (ZoeMO strain) and then treated with either a placebo (tablet containing inert ingredients) or oral moxidectin (ProHeart ${ }^{\circledR}$ tablets shaved to deliver the correct dose). Placebo tablets

Table 1 Study 1 design and efficacy of oral moxidectin against Dirofilaria immitis (JYD-34)

\begin{tabular}{|c|c|c|c|c|c|c|c|}
\hline \multirow[t]{2}{*}{ Group $^{a}(n=8)$} & \multirow[t]{2}{*}{ Treatment $\mathrm{t}^{\mathrm{b}, \mathrm{c}}$} & \multirow[t]{2}{*}{ Dosage $(\mu \mathrm{g} / \mathrm{kg})$} & \multirow[t]{2}{*}{ Days of treatment } & \multirow{2}{*}{$\begin{array}{l}\text { No. of dogs } \\
\text { with worms }\end{array}$} & \multicolumn{3}{|c|}{ Adult D. immitis worm counts ${ }^{d}$} \\
\hline & & & & & Individual worm counts & Geometric mean $^{e}$ & $\%$ reduction \\
\hline T01 & Placebo & na & $0,30,60$ & 8 of 8 & $29,32,33,35,36,39,43,43$ & $35.9^{9}$ & - \\
\hline $\mathrm{T} 02^{\mathrm{f}}$ & Moxidectin & 3 & 0 & 8 of 8 & $20,25,27,29,30,32,35,39$ & $29.1^{\mathrm{h}}$ & 19.0 \\
\hline T03 & Moxidectin & 6 & 0 & 8 of 8 & $19,21,24,25,26,28,35,43$ & $26.8^{h}$ & 25.5 \\
\hline T04 & Moxidectin & 12 & 0 & 8 of 8 & $17,20,20,23,23,26,33,35$ & $24.0^{h, i}$ & 33.3 \\
\hline T05 & Moxidectin & 24 & 0 & 8 of 8 & $7,13,16,16,19,20,24,29$ & $16.8^{i}$ & 53.2 \\
\hline T0 $^{\mathrm{f}}$ & Moxidectin & 3 & $0,30,60$ & 8 of 8 & $7,13,18,21,25,27,29,36$ & $20.0^{h, i}$ & 44.4 \\
\hline
\end{tabular}

a All dogs were inoculated with 50 D. immitis L3 (JYD-34 strain) at Day -30

b To maintain masking, dogs in T02, T03, T04 and T05 were administered an empty hydroxypropyl methycellulose (HPMC) capsule on Days 30 and 60

c Moxidectin administered as HPMC capsules filled with the appropriate amount of hand-pulverized ProHeart ${ }^{\circledR}$ tablets to deliver the correct dose

d All dogs were necropsied for recovery and enumeration of adult heartworms on Day 122 (140 days post-inoculation)

e Means with different superscript letters ( $\mathrm{g}-\mathrm{i})$ are significantly different $\left(2.51 \leq t_{d f} \leq 5.28, P \leq 0.0342\right.$, where $\left.4.65 \leq d f \leq 8.61\right)$

$f$ Conducted as part of this study but first reported in McTier et al. [32]

Abbreviation: na, not applicable 
Table 2 Study 2 design and efficacy of oral moxidectin against Dirofilaria immitis (JYD-34, ZoeLA)

\begin{tabular}{|c|c|c|c|c|c|c|c|c|}
\hline \multirow[t]{2}{*}{ Strain } & \multirow[t]{2}{*}{ Group $^{a}(n=5)$} & \multirow[t]{2}{*}{ Treatment $^{\mathrm{b}}$} & \multirow[t]{2}{*}{ Dosage $(\mu \mathrm{g} / \mathrm{kg})$} & \multirow[t]{2}{*}{ Days of treatment } & \multirow{2}{*}{$\begin{array}{l}\text { No. of dogs } \\
\text { with worms }\end{array}$} & \multicolumn{3}{|c|}{ Adult D. immitis worm counts ${ }^{c}$} \\
\hline & & & & & & Individual worm counts & Geometric mean $^{d}$ & $\%$ reduction \\
\hline \multirow[t]{4}{*}{ JYD-34 } & T01 & Placebo & na & $0,28,56$ & 5 of 5 & $5,23,27,33,33$ & $20.6^{f}$ & - \\
\hline & T03 & Moxidectin & 24 & $0,28,56$ & 1 of 5 & 2 & $0.2^{\mathrm{g}}$ & 98.8 \\
\hline & T04 & Moxidectin & 40 & $0,28,56$ & 0 of 5 & 0 & $0^{9}$ & 100.0 \\
\hline & T05 & Moxidectin & 60 & $0,28,56$ & 0 of 5 & 0 & $0^{g}$ & 100.0 \\
\hline \multirow[t]{6}{*}{ ZoeLA } & T02 & Placebo & na & $0,28,56$ & 5 of 5 & $25,26,31,37,38$ & $30.9^{f}$ & - \\
\hline & T06 & Moxidectin & 3 & 0 & 5 of 5 & $11,13,17,19,25$ & $20.0^{9}$ & 44.4 \\
\hline & T07 & Moxidectin & 24 & $0,28,56$ & 1 of 5 & 1 & $0.1^{\mathrm{h}}$ & 99.5 \\
\hline & T08 & Moxidectin & 40 & $0,28,56$ & 1 of 5 & 1 & $0.1^{\mathrm{h}}$ & 99.5 \\
\hline & T09 & Moxidectin & 60 & 0 & 5 of 5 & $1,1,6,6,10$ & $3.6^{i}$ & 88.2 \\
\hline & $\mathrm{T} 10$ & Moxidectin & 60 & $0,28,56$ & 0 of 5 & 0 & $0^{\text {h }}$ & 100 \\
\hline \multicolumn{9}{|c|}{ a All dogs were inoculated with 50 D. immitis L3 at Day -30. Groups T01 and T03-T05 received the JYD-34 strain; Groups T02 and T06-T10 received the ZoeLA strain } \\
\hline \multicolumn{9}{|c|}{${ }^{\mathrm{b}}$ Moxidectin administered as ProHeart ${ }^{\circledR}$ tablets shaved to deliver the correct dose } \\
\hline \multicolumn{9}{|c|}{ c All dogs were necropsied for recovery and enumeration of adult heartworms on Day 103 (133 days post-inoculation) } \\
\hline \multicolumn{9}{|c|}{$\begin{array}{l}{ }^{d} \text { Means with different superscript letters }(f-i) \text { are significantly different within each strain } t_{(34)}=2.33, P=0.0259 \text { for T02 vs T06; } 7.36 \leq t_{(34)} \leq 13.21, P<0.0001 \text { for all } \\
\text { other significant differences }\end{array}$} \\
\hline \multicolumn{9}{|c|}{ e Percentage reduction is compared to T01 for Groups T03-T05 and compared to T02 for Groups T06-T10 } \\
\hline
\end{tabular}

Table 3 Study 3 design and efficacy of oral moxidectin against Dirofilaria immitis (ZoeMO)

\begin{tabular}{|c|c|c|c|c|c|c|c|}
\hline \multirow[t]{2}{*}{ Group $^{\mathrm{a}}(n=5)$} & \multirow[t]{2}{*}{ Treatment $^{b}$} & \multirow[t]{2}{*}{ Dosage $(\mu \mathrm{g} / \mathrm{kg})$} & \multirow[t]{2}{*}{ Days of treatment } & \multirow{2}{*}{$\begin{array}{l}\text { No. of dogs } \\
\text { with worms }\end{array}$} & \multicolumn{3}{|c|}{ Adult D. immitis worm counts ${ }^{c}$} \\
\hline & & & & & Individual worm counts & Geometric mean $^{d}$ & $\%$ reduction \\
\hline T01 & Placebo & $\mathrm{N} / \mathrm{A}$ & $0,28,56$ & 5 of 5 & $23,31,31,34,36$ & $30.7^{e}$ & - \\
\hline T02 & Moxidectin & 3 & 0 & 5 of 5 & $2,3,5,9,15$ & $5.5^{f}$ & 82.1 \\
\hline T03 & Moxidectin & 24 & $0,28,56$ & 1 of 5 & 1 & $0.1^{\mathrm{g}}$ & 99.5 \\
\hline T04 & Moxidectin & 40 & $0,28,56$ & 0 of 5 & 0 & $0^{g}$ & 100 \\
\hline T05 & Moxidectin & 60 & $0,28,56$ & 0 of 5 & 0 & $0^{9}$ & 100 \\
\hline
\end{tabular}

a All dogs were inoculated with 50 D. immitis L3 (ZoeMO strain) at Day - 28

b Moxidectin administered as ProHeart ${ }^{\circledR}$ tablets shaved to deliver the correct dose

c All dogs were necropsied for recovery and enumeration of adult heartworms on Day 120 (148 days post-inoculation)

${ }^{d}$ Means with different superscript letters $(e-g)$ are significantly different $\left(7.34 \leq t_{(16)} \leq 16.0, P<0.0001\right)$

Abbreviation: na, not applicable

were given on Days 0, 28 and 56. Moxidectin treatments were administered on Day 0 only at $3 \mu \mathrm{g} / \mathrm{kg}$ (T02) or on Days 0, 28 and 56 at 24 (T03), 40 (T04) or $60 \mu \mathrm{g} / \mathrm{kg}$ (T05) (Table 3). Preventive efficacy was evaluated at Day 120 (148 days post-inoculation) following necropsy and adult worm recovery and enumeration.

\section{Animals}

Individually identified, purpose-bred intact male and female beagles 7-18 months of age at the time of infection were used in all three studies. All animals received a physical examination by a veterinarian to determine health and suitability for inclusion in the study. Animals weighed between $6.8-14.3 \mathrm{~kg}$ at the time of study initiation and were acclimated for 5-9 days prior to inoculation.
All dogs were housed individually within a mosquitoproof facility in indoor cages that complied with accepted animal welfare legislation and guidance. They were fed an appropriate maintenance diet of a commercial dry canine ration and had access to water ad libitum. Standard environmental conditions were maintained and environmental enrichment and social interactions were provided. Treatment groups ( $n=8$, Study $1 ; n=5$, Studies 2 and 3 ) consisted of approximately equal numbers of male and female dogs. No dog had ever received ProHeart ${ }^{\circledR} 6$ or any ML-containing product within 90 days prior to the start of the study.

Dogs were determined to be free of HW infection by modified Knott's test, and commercially available adult HW antigen tests (DiroCHEK ${ }^{\circledR}$ or WITNESS $^{\circledR}$ Heartworm Antigen Test Kit, Zoetis, Parsippany; SNAP 
Heartworm RT Test, Idexx, Westbrook, ME, USA; Solo Step ${ }^{\circledR}$ Canine Heartworm Test, Heska, Loveland, CO, USA) at least 1 week prior to L3 inoculation. Heat treatment of serum prior to HW antigen testing was not performed. To identify any infections not previously detectable at study start, additional blood samples were collected on Day 59 (Studies 1 and 3) or Day 60 (Study 2) and examined for D. immitis microfilariae and tested for adult $D$. immitis antigen. In Study 1, blood samples were also collected on Days 104 and 122 and examined for adult $D$. immitis antigen to detect infection due to experimental inoculation.

\section{Heartworm strains}

The HW strains used in the studies were derived from isolates recently (within the previous 5 years of initial testing) collected from naturally infected dogs from the middle to southeastern USA. JYD-34 (Studies 1 and 2) was originally collected from a naturally occurring field case of canine HW in Illinois in July 2010. ZoeMO-2012 (ZoeMO) (Study 3) was collected in December 2012 from the same dog from which the original JYD-34 strain had been collected 2.5 years earlier (J. McCall, personal oral communication, 2013). The dog had been maintained in mosquito-proof quarters with no additional administration of macrocyclic lactones during the intervening time. ZoeLA (Study 2) was collected from a naturally occurring field case of canine HW in Louisiana in June 2013. All three isolates were validated as infective strains through the diagnosis of circulating microfilariae, positive heartworm antigen test results and adult worm recovery in recipient animals. Additional details on these strains are provided by McTier et al. [32].

\section{Dirofilaria immitis inoculations}

Dogs in all studies were administered 50 viable L3 in RPMI balanced media solution by subcutaneous injection in the inguinal region. Larvae were harvested from infected Aedes aegypti mosquitoes reared and maintained at Zoetis (Kalamazoo, MI, USA) as previously described [6]. Studies were conducted within 4 years of the heartworm isolate collection from the field.

\section{Treatments}

For all studies, moxidectin was supplied as commercial ProHeart ${ }^{\circledR}$ tablets (30, 68 and $136 \mu \mathrm{g}$ of moxidectin/tablet) that were obtained as commercial products directly from the Zoetis manufacturer (Fort Dodge, IA, USA); these tablets were produced for markets in Japan and/ or Australia. The correct size and number of tablets were selected based on the total dosage of moxidectin needed. Tablets were pulverized and placed in HPMC capsules or shaved to deliver the exact calculated point dose of moxidectin, based on individual body weights obtained within 8 days of each treatment. In all studies, capsules/ tablets were administered by mouth along with $5 \mathrm{ml}$ of water to encourage swallowing. Treatment was carried out following overnight fasting, and each dog was then offered its regular food ration within $2 \mathrm{~h}$ of dosing. Dogs were observed for several minutes after dosing to confirm that the dose was swallowed and to monitor for potential adverse events.

\section{Study 1}

Dogs in the moxidectin-treated groups (Groups T02T06) were administered capsules filled with the appropriate amount of hand-pulverized moxidectin, with dosage calculated based on the individual body weights recorded on Day -8 (Day 0 dosing), Day 23 (Day 30 dosing) or Day 53 (Day 60 dosing). The moxidectin-filled capsules were administered to dogs in T02-T05 on Day 0 only and to dogs in T06 on Days 0, 30 and 60 (see Table 1). To maintain masking, dogs in T02-T05 were administered an empty capsule on Days 30 and 60, and dogs in the control group (T01) were administered an empty capsule on Days 0, 30 and 60.

\section{Study 2}

Dogs in the moxidectin-treated groups (T03-T10) were administered ProHeart ${ }^{\circledR}$ tablets shaved/sanded to the appropriate dose for the body weight determined for each individual dog on Day - 3 (Day 0 dosing), Day 25 (Day 28 dosing) or Day 53 (Day 56 dosing). The moxidectin tablets were administered to dogs in T06 and T09 on Day 0 only and to dogs in T03-T05, T07-T08 and T10 on Days 0, 28 and 56 (see Table 2). Dogs in T01 and T02 were administered one whole placebo tablet (containing vehicle only) on Days 0, 28 and 56.

\section{Study 3}

Dogs in the moxidectin-treated groups (T02-T05) were administered ProHeart ${ }^{\circledR}$ tablets sanded/shaved so that each dog received the appropriate dose based on the individual body weight recorded on Day -5 (Day 0 dosing), Day 27 (Day 28 dosing) or Day 55 (Day 56 dosing). Dogs in T03-T05 were dosed on Days 0, 28 and 56, whereas dogs in T02 were dosed on Day 0 only (Table 3). Dogs in T01 were administered one whole placebo tablet on Days 0,28 and 56 .

\section{Animal observations}

Physical examinations were performed by a veterinarian immediately prior to the start of each study (Day 
$-60,-35$ or -34 for Study 1, 2 or 3, respectively) and included, but were not limited to, rectal temperature, thoracic auscultation, skin and hair coat assessment, and the general physical condition of each dog. General health observations were made for each dog either once (Studies 2 and 3) or twice (Study 1) daily. Clinical observations were made on all animals prior to and at 1, 3, 6 and $24 \mathrm{~h}$ after the administration of vehicle or test product on Days 0, 30 and 60 (Study 1) or on Days 0, 28 and 56 (Studies 2 and 3). All personnel conducting observations were masked to treatment allocations and changed protective clothing between handling each dog.

\section{Necropsy and parasite recovery}

Dogs were humanely euthanized after an intravenous injection of heparin via an approved pentobarbital euthanasia solution on Day 122 (Study 1), Day 103 (Study 2) or Day 120 (Study 3). The pleural and peritoneal cavities were examined for adult $D$. immitis, the posterior and anterior vena cavae were clamped, and the heart and lungs were removed. The precava, right atrium, right ventricle and pulmonary arteries (including those coursing through the lungs) were dissected and examined. Any adult worms present were recovered and classified as male or female and as either dead (worms abnormal in both appearance and motility) or alive (all other worms) as previously described [42]. Dogs were randomly assigned to order of euthanasia and necropsy.

\section{Data analysis}

The experimental unit for treatment was the individual dog. Within each study, the numbers of adult $D$. immitis recovered during post mortem examinations were summarized for each treatment group. The natural $\left[\log _{\mathrm{e}}\right.$ $(\mathrm{x}+1)$ ] transformation was applied to all counts prior to analysis, and the geometric means (back-transformed least squares means) were calculated.

Percent efficacy, relative to the control group and based on geometric means, was calculated as follows:

$$
\% \text { Efficacy }=\frac{(\text { Mean Control }- \text { Mean Treated })}{\text { Mean Control }} \times 100
$$

Treatment differences were assessed between control and treated groups using contrasts in a general linear mixed model analysis of natural logarithm transformed worm counts and a significance level of $\alpha=0.05$. The models included the fixed effect of treatment and random effects of room (study 2 only), block within room, and error. SAS PROC MIXED was used to fit the statistical models and the Kenward-Roger option was used to calculate degrees of freedom for the test-statistics used for pairwise treatment comparisons. All analyses were carried out using SAS/STAT Release 9.3 (SAS Institute, Cary, NC, USA).

\section{Results \\ Efficacy}

In each study, control dogs inoculated with each $D$. immitis strain were positive for adult worms at necropsy, and worm counts confirmed the adequacy of the infections (Tables 1, 2, 3). Geometric mean (range) HW counts for untreated dogs inoculated with the JYD-34 strain were 35.9 (29-43) in Study 1 (T01) and 20.6 (5-33) in Study 2 (T01). Control dogs inoculated with ZoeLA in Study 2 (T02) and ZoeMO in Study 3 (T01) harbored a geometric mean (range) of 30.9 (25-38) and 30.7 (23-36) adult HWs, respectively.

In all three studies, all dogs administered moxidectin (at every dose and with every regimen) showed significantly reduced adult worm counts compared to control dogs (Study 1, 2.51 $\leq t_{d f} \leq 5.28, P \leq 0.0342$, where $4.65 \leq d f \leq 8.61$; Study $2,7.36 \leq t_{(34)} \leq 13.21, \quad P<0.0001$ for all treatments except for a single dose of moxidectin at $3 \mu \mathrm{g} / \mathrm{kg}$ (T02), $t_{(34)}=2.33, P=0.0259$; Study 3 , $7.34 \leq t_{(16)} \leq 16.0, P<0.0001$ ) (Tables 1, 2, 3).

In Study 1, dogs treated with a single dose of moxidectin at $3 \mu \mathrm{g} / \mathrm{kg} 30$ days after inoculation with $D$. immitis JYD-34 L3 showed a 19.0\% reduction in mean worm counts compared with control dogs. Administering the same dose for three consecutive months increased the level of protection to $44.4 \%$, higher than that achieved with a single dose of moxidectin at $12 \mu \mathrm{g} / \mathrm{kg}(33.3 \%)$ and approaching the efficacy of one dose at $24 \mu \mathrm{g} / \mathrm{kg}(53.2 \%)$ (Table 1); however, all dogs in all groups were infected with HW regardless of dose and regimen used. In Study 2, efficacy of moxidectin against JYD-34 was further improved when dogs were given moxidectin for three consecutive months; $>98 \%$ efficacy was obtained at 24 $\mu \mathrm{g} / \mathrm{kg}$ (T03) with only 1 of 5 dogs infected, and $100 \%$ efficacy was demonstrated with three treatments of both 40 (T04) and $60 \mu \mathrm{g} / \mathrm{kg}$ (T05) (Table 2).

Dogs inoculated with the $D$. immitis ZoeMO strain (Study 3) showed similar results to those obtained using the JYD-34 strain when treated with three consecutive monthly dosages of moxidectin; only one dog treated with $24 \mu \mathrm{g} / \mathrm{kg}$ moxidectin had a single worm at necropsy, and a dose of either 40 (T04) or $60 \mu \mathrm{g} / \mathrm{kg}$ (T05) was $100 \%$ effective in preventing the development of $D$. immitis (Table 3).

Treating with three dosages of moxidectin at 24 or $40 \mu \mathrm{g} / \mathrm{kg}$ (Study 2, T07 and T08, respectively) provided $>99 \%$ efficacy in dogs inoculated with the ZoeLA strain, with 1 of 5 dogs infected. A similar pattern was observed at $60 \mu \mathrm{g} / \mathrm{kg}$, with a single dose (T09) providing $88.2 \%$ 
efficacy (5 of 5 dogs infected) and three dosages (T10, Study 2) providing complete prevention in all dogs.

\section{Health observations}

There were no mortalities among the dogs involved in any of the three studies. Various abnormal health observations were made sporadically during these studies across all treatment groups (e.g. emesis, soft stool, diarrhea, abrasions, broken toenail, interdigital cyst, prolapsed nictitans gland). Most signs resolved with either no or minimal treatment (e.g. temporary anti-inflammatory or antimicrobial administration). All clinical signs recorded during the studies were deemed to be unrelated to treatment with moxidectin.

\section{Discussion}

The increasing number of HW LOE reports in dog populations across the USA is well documented. Between 2000 and 2002, the number of LOE cases reported to the US Food and Drug Administration, Center for Veterinary Medicine rose from 405 to 951, and the following 12 months (2002-2003) saw another increase to 1503 [22]. Twenty years after the first LOE reports, analyses to determine patterns of LOE are being conducted on more than 45,000 LOE cases reported between 2004 and 2015 with preliminary results available [24]. The exact role of ML resistance in these LOE cases remains unclear, but with more than 15 ML-resistant strains already identified and all presently marketed MLs showing less than 100\% efficacy against at least one of these strains in laboratory studies, it is apparent that resistance in D. immitis strains to MLs is real and has the potential to become more widespread [26, 27, 30, 32, 33, 43]. It is therefore important that new treatment options be available to protect dogs exposed to D. immitis populations with reduced susceptibility to MLs.

The three strains used in the present evaluations, JYD-34, ZoeMO and ZoeLA, have been well characterized as ML-resistant [32, 36, 37]. Additionally, data reported here and in previous publications show differences in the strains' susceptibilities to moxidectin and other MLs [25, 27, 32, Tom L. McTier, pers.comm.]. As reported by McTier et al. [32], the efficacy of a single oral dose of moxidectin at $3 \mu \mathrm{g} / \mathrm{kg}$ varied greatly across the strains, with efficacies of $19.0 \%$ for JYD-34, $44.4 \%$ for ZoeLA and $82.1 \%$ for ZoeMO, while six consecutive monthly oral dosages of milbemycin oxime $(0.5 \mathrm{mg} /$ $\mathrm{kg}$ ) was only $72.2 \%$ effective against the JYD-34 resistant strain ([44]; Table 4) and three monthly dosages of oral ivermectin $(6 \mu \mathrm{g} / \mathrm{kg})$ was only $29.0 \%$ effective against this same strain [25] (Table 4). The variations in susceptibility to moxidectin and other MLs can likely be explained by genetic differences displayed among the strains. The identification of 42 single nucleotide polymorphisms (SNPs) with alternative alleles known to be associated with ML resistance has shed some light on this phenomenon, with frequency of specific alternative alleles being associated with the strength of the resistant phenotype [27, 36]. Using a pool of 16 D. immitis strains (including JYD-34, ZoeMO and ZoeLA) well characterized in terms of their response to MLs, Bourguinat et al. [36] produced a heat map of ML response and the frequency of the alternative allele at all of the 42 SNP positions and identified nine SNPs most strongly correlated with ML phenotypic response. For the three strains used in our studies, the heat map shows all (JYD-34) or almost all (ZoeMO, ZoeLA) of these 9 SNPs with increased frequencies of the alternative alleles, although across the three strains there are differences in the frequency of the alternative alleles represented at each SNP. Particularly interesting are the efficacy and genetic differences observed between JYD34 and ZoeMO, which were isolated from the same dog with ZoeMO isolated 2.5 years after the original JYD34 strain was taken, suggesting potential reversion of resistance to a more susceptible state over time [32, $36,37,45]$. These differences warrant further study to understand efficacy variations among resistant strains and how resistance might fluctuate in a dynamic population under drug pressure.

Historically, moxidectin has been shown to be the most potent of the MLs in preventing the development of $D$. immitis in dogs when compared across various effectiveness studies [8, 46-48]. As originally tested, a single oral dose of only $0.5 \mu \mathrm{g} / \mathrm{kg}$ moxidectin provided $100 \%$ prevention of $\mathrm{HW}$ development when administered 60 days after larval inoculation [8]. The higher preventive efficacy against $D$. immitis provided by moxidectin likely rests in its inherent potency and its physicochemical and pharmacokinetic properties [39, 49]. Moxidectin generally has a longer elimination half-life and larger volume of distribution than both ivermectin and milbemycin [50-52]. These characteristics result in moxidectin being distributed into host tissues, especially adipose tissue [53]. Moxidectin in adipose tissue remains active against migrating stages of parasites such as HW larvae. Over time, the moxidectin that was distributed to tissue will return to systemic circulation as active compound prior to elimination $[2,3,39,54]$. Data in cattle suggest there is a high correlation between the plasma and adipose tissue concentration of moxidectin [53]. This results in longer persistence in the target host and helps explain the increased duration of efficacy compared to other MLs [49]. Collectively these attributes may explain the greater activity of moxidectin against HW larvae in the face of emerging ML resistance compared to other MLs. 
Table 4 Summary of macrocyclic lactone preventives for efficacy against Dirofilaria immitis (JYD-34 strain) in dogs

\begin{tabular}{|c|c|c|c|c|c|c|c|}
\hline \multirow[t]{2}{*}{ Compound } & \multirow{2}{*}{$\begin{array}{l}\text { Day inoculated } \\
\text { with } \mathrm{L}^{\mathrm{a}}\end{array}$} & \multicolumn{2}{|l|}{ Treatment regimen } & \multicolumn{3}{|l|}{ Results } & \multirow[t]{2}{*}{ Reference } \\
\hline & & $\begin{array}{l}\text { Macrocyclic } \\
\text { lactone dose }\end{array}$ & Day & $\begin{array}{l}\text { No. of dogs } \\
\text { with worms }\end{array}$ & Mean $^{\mathrm{b}}$ (range) & Efficacy (\%) & \\
\hline \multirow{8}{*}{$\begin{array}{l}\text { Moxidectin } \\
\text { (ProHeart }^{\circledR} \\
\text { tablets) }\end{array}$} & -30 & $3 \mu \mathrm{g} / \mathrm{kg}$ & 0 & 8 of 8 & $29.1(20-39)$ & 19.0 & $\begin{array}{l}\text { McTier et al. [32]; this } \\
\text { paper }\end{array}$ \\
\hline & -30 & $3 \mu \mathrm{g} / \mathrm{kg}$ & $0,30,60$ & 8 of 8 & $20.0(7-36)$ & 44.4 & $\begin{array}{l}\text { McTier et al. [32]; this } \\
\text { paper }\end{array}$ \\
\hline & -30 & $6 \mu \mathrm{g} / \mathrm{kg}$ & 0 & 8 of 8 & $26.8(19-43)$ & 25.5 & This paper \\
\hline & -30 & $12 \mu \mathrm{g} / \mathrm{kg}$ & 0 & 8 of 8 & $24.0(17-35)$ & 33.3 & This paper \\
\hline & -30 & $24 \mu \mathrm{g} / \mathrm{kg}$ & 0 & 8 of 8 & $16.8(7-29)$ & 53.2 & This paper \\
\hline & -30 & $24 \mu \mathrm{g} / \mathrm{kg}$ & $0,28,56$ & 1 of 5 & $0.2(0-2)$ & 98.8 & This paper \\
\hline & -30 & $40 \mu \mathrm{g} / \mathrm{kg}$ & $0,28,56$ & 0 of 5 & 0 & 100 & This paper \\
\hline & -30 & $60 \mu \mathrm{g} / \mathrm{kg}$ & $0,28,56$ & 0 of 5 & 0 & 100 & This paper \\
\hline $\begin{array}{l}\text { Moxidectin- } \\
\text { injectable } \\
\text { (ProHeart }{ }^{\circledR} \text { 6) }\end{array}$ & 2 & $0.17 \mathrm{mg} / \mathrm{kg}$ & 0 & 1 of 6 & $0.1(0-1)$ & 99.5 & Bowman et al. [29] \\
\hline $\begin{array}{l}\text { Moxidectin_topi- } \\
\text { cal (Advantage } \\
\text { Multi: imidaclo- } \\
\text { prid/moxidectin) }\end{array}$ & -30 & $2.8-6.7 \mathrm{mg} / \mathrm{kg}$ & 0 & 0 of 8 & 0 & 100 & Blagburn et al. [25] \\
\hline $\begin{array}{l}\text { Ivermectin_oral } \\
\text { (Heartgard }{ }^{\circledR} \text { Plus } \\
\text { Chewables for } \\
\text { Dogs: ivermectin/ } \\
\text { pyrantel pamo- } \\
\text { ate) }\end{array}$ & -30 & $6.2-11.9 \mu \mathrm{g} / \mathrm{kg}$ & $0,31,60$ & 8 of 8 & $13.1(5-19)$ & 29.0 & Blagburn et al. [25] \\
\hline $\begin{array}{l}\text { Selamectin-topi- } \\
\left.\text { cal (Revolution }{ }^{\circledR}\right)\end{array}$ & -30 & $6.6-13.1 \mathrm{mg} / \mathrm{kg}$ & $0,31,60$ & 8 of 8 & $8.8(3-18)$ & 28.8 & Blagburn et al. [25] \\
\hline $\begin{array}{l}\text { Milbemycin } \\
\text { oxime-oral } \\
\text { (Trifexis }^{\circledR} \text { Chewa- } \\
\text { bles for Dogs: } \\
\text { milbemycin } \\
\text { oxime/spinosad) }\end{array}$ & -30 & $0.5-1.0 \mathrm{mg} / \mathrm{kg}$ & $0,31,60$ & 8 of 8 & $13.1(9-18)$ & 52.2 & Blagburn et al. [25] \\
\hline $\begin{array}{l}\text { Milbemycin } \\
\text { oxime-oral } \\
\text { (Interceptor }^{\circledR} \text { : } \\
\text { milbemycin } \\
\text { oxime) }\end{array}$ & $-30,-23^{d}$ & $0.92 \pm 0.15 \mathrm{mg} / \mathrm{kg}^{\mathrm{e}}$ & 0 & 8 of 8 & $9.3(0-39)$ & 58.2 & McCall et al. [55] \\
\hline $\begin{array}{l}\text { Milbemycin } \\
\text { oxime (NexGard } \\
\left.\text { Spectra }{ }^{\circledR}\right)\end{array}$ & -30 & $0.5-1.0 \mathrm{mg} / \mathrm{kg}$ & 0,30 & na & na & 76.1 & $\begin{array}{c}\text { NexGard Spectra }{ }^{\circledR} \\
\text { EPAR, } 2014[44]\end{array}$ \\
\hline $\begin{array}{l}\text { Milbemycin } \\
\text { oxime (NexGard } \\
\left.\text { Spectra }{ }^{\circledR}\right)\end{array}$ & -30 & $0.5-1.0 \mathrm{mg} / \mathrm{kg}$ & $0,30,60$ & na & na & 72.2 & $\begin{array}{c}\text { NexGard Spectra }{ }^{\circledR} \\
\text { EPAR, } 2014[44]\end{array}$ \\
\hline $\begin{array}{l}\text { Milbemycin } \\
\text { oxime (NexGard } \\
\left.\text { Spectra }{ }^{\circledR}\right)\end{array}$ & -30 & $0.5-1.0 \mathrm{mg} / \mathrm{kg}$ & $\begin{array}{l}0,30,60,90,120, \\
150\end{array}$ & na & na & 72.0 & $\begin{array}{l}\text { NexGard Spectra }{ }^{\circledR} \\
\text { EPAR, } 2014 \text { [44] }\end{array}$ \\
\hline
\end{tabular}

a Day of first treatment is designated as Day 0. All dogs inoculated with $50 \mathrm{~L} 3$ unless otherwise specified

b Geometric means (arithmetic means for McCall et al. [55])

c Less than $100 \%$ efficacy was obtained with $2.5 \mathrm{mg} / \mathrm{kg}$ topical moxidectin in a similar study (Dr John McCall, personal communication)

$d$ Dogs infected with an estimated total of $78 \pm 14 \mathrm{~L} 3$ via two exposures to infected mosquitoes

e Mean dose administered

Abbreviations: EPAR, European Public Assessment Report; na, data not available 
The present studies demonstrated that increasing both the dose and the frequency (consecutive monthly dosages) of oral moxidectin increased the efficacy against all three ML-resistant HW strains (JYD-34, ZoeLA and ZoeMO) evaluated, with three consecutive monthly dosages of $\geq 40 \mu \mathrm{g} / \mathrm{kg}$ moxidectin providing complete preventive efficacy. Additionally, three dosages of moxidectin at $24 \mu \mathrm{g} / \mathrm{kg}$ was highly effective ( $\geq 98.8 \%)$ in preventing the development of all three HW strains, with only a single dog in each group ( 1 of 5 ) having just one or two worms. This high level of protection against MLresistant $D$. immitis strains provided by repeated dosages has not been reported for any of the present commercially available oral preventives (only $29.0 \%$ and $\leq 72.2 \%$ efficacy with three consecutive monthly dosages of ivermectin or three to six consecutive monthly dosages of milbemycin oxime respectively; Table 4).

Furthermore, based on the existing very high efficacy ( $\geq 98.8 \%$; 4 of 5 dogs heartworm free) obtained after three months of dosing with $24 \mu \mathrm{g} / \mathrm{kg}$ moxidectin against all three resistant strains and the unique attributes of the moxidectin molecule, it is likely that four or more consecutive monthly dosages of $24 \mu \mathrm{g} / \mathrm{kg}$ moxidectin may provide additional protection. This dose should provide robust HW preventive efficacy against the strains to which most dogs in the USA will be exposed, including $D$. immitis populations with reduced susceptibility to MLs, with an adequate margin of safety in the most sensitive patient population (collies). For these reasons, $24 \mu \mathrm{g} / \mathrm{kg}$ moxidectin was selected as the optimal dose for further commercial development in a new oral HW preventive.

\section{Conclusions}

Increasing both the dose and the number of consecutive monthly oral dosages of moxidectin resulted in increased preventive efficacy against ML-resistant $D$. immitis with complete protection obtained using three dosages of moxidectin at either $40 \mu \mathrm{g} / \mathrm{kg}$ (JYD-34, ZoeMO) or 60 $\mu \mathrm{g} / \mathrm{kg}$ (ZoeLA). Three consecutive monthly dosages of 24 $\mu \mathrm{g} / \mathrm{kg}$ moxidectin provided very high efficacy $(\geq 98.8 \%$ efficacy with 4 out of 5 dogs heartworm-free) against all three ML-resistant strains. Moxidectin administered at $24 \mu \mathrm{g} / \mathrm{kg}$ was selected as the optimal oral dose to develop as a safe and effective means of protecting dogs against HW disease in the face of increasing ML resistance.

\footnotetext{
Abbreviations

ML: macrocyclic lactone; HW: heartworm; AHS: American Heartworm Society; LOE: lack of efficacy; JYD-34: Dirofilaria immitis strain JYD-34; ZoeLA: Dirofilaria immitis strain ZoeLA-2013; AMAL: Dirofilaria immitis strain AMAL-2014; ZoeMO: Dirofilaria immitis strain ZoeMO-2012; LMRV: lower Mississippi River valley; CVM: Center for Veterinary Medicine; L3: third-stage larvae; HPMC: hydroxypropyl methycellulose; SNP: single nucleotide polymorphism.
}

\section{Acknowledgements}

The Zoetis staff and the staff of Cheri Hill Kennel and Supply, Inc. are gratefully acknowledged for their dedication to the study execution. Sharon Chirgwin

DeRosa is acknowledged for assistance in drafting the manuscript.

\section{Authors' contributions}

TM, RS, SPM, SM and DW conceived the study designs. TM and SM drafted the manuscript. AP, SC and KK contributed to various aspects of conducting the studies. All authors critically reviewed the draft of the manuscript. All authors read and approved the final manuscript.

\section{Funding}

The studies reported here were funded by Zoetis, Kalamazoo, MI, USA.

\section{Availability of data and materials}

All relevant data supporting the conclusions of this article are included within the article.

\section{Ethics approval and consent to participate}

Laboratory study protocols were reviewed and approved by the Institutional Animal Care and Use Committee at each facility. All three studies were conducted according to state and national regulations regarding animal welfare.

\section{Consent for publication}

Not applicable.

\section{Competing interests}

TLM, AP, SC, KK, SPM, DW and SM are current employees of Zoetis. RS is a former employee of Zoetis.

Received: 12 June 2019 Accepted: 23 Auqust 2019

Published online: 11 September 2019

\section{References}

1. Arther RG, Bowman DD, Slone RL, Travis LE. Imidacloprid plus moxidectin topical solution for the prevention of heartworm disease (Dirofiloria immitis) in dogs. Parasitol Res. 2005;97(Suppl. 1):S76-80.

2. Bowman DD, Grazette AR, Basel C, Wang Y, Hostetler JA. Protection of dogs against canine heartworm infection 28 days after four monthly treatments with Advantage Multi ${ }^{\circledR}$ for Dogs. Parasit Vectors. 2016;9:12.

3. Bowman DD, Ohmes CM, Hostetler JA, Keil DJ, Settje TL, Charles SD. Efficacy of $10 \%$ imidacloprid $+2.5 \%$ moxidectin topical solution (Advantage Multi ${ }^{\circledR}$ for Dogs) for the prevention of heartworm disease and infection all month long. Parasit Vectors. 2017:10(Suppl. 2):478.

4. Lok JB, Knight DH, McCall JW, Dzimianski MT, Cleale RM, Wang GT, et al. Six-month prophylactic efficacy of an injectable, sustained-release formulation of moxidectin against Dirofilaria immitis infection: a two-center study. Recent advances in heartworm disease-symposium '01. Batavia: American Heartworm Society; 2001. p. 149-57.

5. Lok JB, Knight DH, Wang GT, Doscher ME, Nolan TJ, Hendrick MJ, et al. Activity of an injectable, sustained-release formulation of moxidectin administered prophylactically to mixed-breed dogs to prevent infection with Dirofilaria immitis. Am J Vet Res. 2001;62:1721-6.

6. McCall JW, Lindemann BA, Porter CA. Prophylactic activity of avermectins against experimentally induced Dirofilaria immitis in dogs. In: Proceedings of the heartworm symposium ' 80 . Edwardsville: Veterinary Medicine Publishing Co.; 1980. p. 126-30.

7. McCall JW, McTier TL, Holmes RA, Greene T, Strickland J, Aguilar R. Prevention of naturally acquired heartworm infection in heartworm-negative beagles by oral administration of moxidectin at an interval of either one or two months. In: Proceedings of the Heartworm Symposium ' 92. Batavia: American Heartworm Society; 1992. p. 169-77.

8. McTier TL, McCall JW, Dzimianski MT, Aguilar R, Wood I: Prevention of experimental heartworm infection in dogs with single oral doses of moxidectin. In: Proceedings of the Heartworm Symposium '92. Batavia: American Heartworm Society; 1992. p. 165-8.

9. McTier TL, Shanks DJ, Watson P, McCall JW, Genchi C, Six RH, et al. Prevention of experimentally induced heartworm (Dirofilaria immitis) infections 
in dogs and cats with a single topical application of selamectin. Vet Parasitol. 2000;91:259-68.

10. Snyder DE, Wiseman S, Bowman DD, McCall JW, Reinemeyer CR. Assessment of the effectiveness of a combination product of spinosad and milbemycin oxime on the prophylaxis of canine heartworm infection. Vet Parasitol. 2011;180:262-6.

11. Snyder DE, Wiseman S, Cruthers LR, Slone RL. Ivermectin and milbemycin oxime in experimental adult heartworm (Dirofilaria immitis) infection of dogs. J Vet Intern Med. 2011;25:61-4

12. Cabanova V, Miterpakova M, Valentova D, Blazejova H, Rudolf I, Stloukal E, et al. Urbanization impact on mosquito community and the transmission potential of filarial infection in central Europe. Parasit Vectors. 2018;11:261.

13. Drake J, Wiseman S. Increasing incidence of Dirofilaria immitis in dogs in USA with focus on the southeast region 2013-2016. Parasit Vectors. 2018;11:39.

14. Genchi C, Bowman D, Drake J. Canine heartworm disease (Dirofilaria immitis) in western Europe: survey of veterinary awareness and perceptions. Parasit Vectors. 2014;7:206.

15. Morchon R, Carreton E, Gonzalez-Miguel J, Mellado-Hernandez I. Heartworm disease (Dirofilaria immitis) and their vectors in Europe-new distribution trends. Front Physiol. 2012;3:196.

16. Rehm CJ. AHS survey finds increase in heartworm cases: is heartworm incidence up or down in your practice area? American Heartworm Society Quarterly Update, Summer 2017. https://d3ft8sckhnqim2.cloud front.net/images/bulletin/AHS-1705-May-17-Summer-Bulletin.pdf?15350 50388. Accessed 18 Aug 2019

17. Companion Animal Parasite Council. Controlling internal and external parasites in US dogs and cats. 2017. http://www.petsandparasites.org/ resources/capc-guidelines. Accessed 22 May 2019.

18. American Heartworm Society. Interpreting the new 2016 AHS heartworm incidence map. American Heartworm Society Bulletin. 2017; 44(2). https ://d3ft8sckhnqim2.cloudfront.net/images/bulletin/AHS_Jun_17_Bulle tin_for_Web.pdf?1496160824. Accessed 18 Aug 2019.

19. Atkins CE, Murray MJ, Olavessen LJ, Burton KW, Marshall JW, Brooks CC. Heartworm 'lack of effectiveness' claims in the Mississippi Delta: computerized analysis of owner compliance-2004-2011. Vet Parasitol. 2014:206:106-13.

20. Ballesteros C, Pulaski CN, Bourguinat C, Keller K, Prichard RK, Geary TG. Clinical validation of molecular markers of macrocyclic lactone resistance in Dirofilaria immitis. Int J Parasitol Drugs Drug Resist. 2018;8:596-606.

21. Geary TG, Bourguinat C, Prichard RK. Evidence for macrocyclic lactone anthelmintic resistance in Dirofilaria immitis. Top Comput Anim Med. 2011;26:186-92.

22. Hampshire VA. Evaluation of efficacy of heartworm preventive products at the FDA. Vet Parasitol. 2005;133:191-5.

23. McTier TL, Kryda K, Wachowski M, Ramsey D, Mahabir SP, Rugg D, et al. ProHeart ${ }^{\circledR} 12$, a moxidectin extended-release injectable formulation for prevention of heartworm (Dirofilaria immitis) disease in dogs in the USA for 12 months. Parasit Vectors. 2019;12:369.

24. Pulaski C, Shibukawa-Kent R, Bright-Ponte S, Duggirala H, Baker J, Malone JB, Kaplan, R. Heartworm preventive drug 'lack of effectiveness' claims submitted to the FDA (2004-2015): an analysis of reports and further application. American Association of veterinary parasitologists 62nd annual meeting, July 22-25. 2017.

25. Blagburn BL, Arther RG, Dillon AR, Butler JM, Bowles JV, von Simson C, Zolynas R. Efficacy of four commercially available heartworm preventive products against the JYD-34 laboratory strain of Dirofilaria immitis. Parasit Vectors. 2016;9:191

26. Bourguinat $\mathrm{C}$, Che H, Mani T, Keller K, Prichard RK. ABC-B transporter genes in Dirofilaria immitis. Int J Parasitol Drugs Drug Resist. 2016;6:116-24

27. Bourguinat C, Lee AC, Lizundia R, Blagburn BL, Liotta JL, Kraus MS, et al. Macrocyclic lactone resistance in Dirofilaria immitis: failure of heartworm preventives and investigation of genetic markers for resistance. Vet Parasitol. 2015:210:167-78.

28. Bowman DD. Heartworms, macrocyclic lactones, and the specter of resistance to prevention in the United States. Parasit Vectors. 2012;5:138

29. Bowman DD, McTier TL, Adams EL, Mahabir SP, Login JA, Bidgood T, Woods DJ. Evaluation of the efficacy of ProHeart ${ }^{\circledR} 6$ (moxidectin) against a resistant isolate of Dirofilaria immitis (JYD-34) in dogs. Parasit Vectors. 2017;10(Suppl. 2):502.

30. Maclean MJ, Savadelis MD, Coates R, Dzimianski MT, Jones C, Benbow $C$, et al. Does evaluation of in vitro microfilarial motility reflect the resistance status of Dirofilaria immitis isolates to macrocyclic lactones? Parasit Vectors. 2017;10(Suppl. 2):480.

31. McTier TL, Pullins A, Inskeep GA, Gagnon G, Fan H, Schoell A, et al. Microfilarial reduction following ProHeart ${ }^{\circledR} 6$ and ProHeart ${ }^{\circledR}$ SR-12 treatment in dogs experimentally inoculated with a resistant isolate of Dirofilaria immitis. Parasit Vectors. 2017;10(Suppl. 2):485.

32. McTier TL, Six RH, Pullins A, Chapin S, McCall JW, Rugg D, et al. Efficacy of oral moxidectin against susceptible and resistant isolates of Dirofilaria immitis in dogs. Parasit Vectors. 2017;10(Suppl. 2):482.

33. Pulaski CN, Malone JB, Bourguinat C, Prichard R, Geary T, Ward D, et al. Establishment of macrocyclic lactone resistant Dirofilaria immitis isolates in experimentally infected laboratory dogs. Parasit Vectors. 2014;7:494

34. Bourguinat C, Keller K, Blagburn B, Schenker R, Geary TG, Prichard RK. Correlation between loss of efficacy of macrocyclic lactone heartworm anthelmintics and P-glycoprotein genotype. Vet Parasitol. 2011;176:374-81

35. Bourguinat C, Keller K, Prichard RK, Geary TG. Genetic polymorphism in Dirofilaria immitis. Vet Parasitol. 2011;176:368-73.

36. Bourguinat C, Keller K, Xia J, Lepage P, McTier TL, Woods DJ, et al. Genetic profiles of ten Dirofilaria immitis isolates susceptible or resistant to macrocyclic lactone heartworm preventives. Parasit Vectors. 2017;10(Suppl. 2):504.

37. Bourguinat C, Lefebvre F, Sandoval J, Bondesen B, Moreno Y, Prichard RK. Dirofilaria immitis JYD-34 isolate: whole genome analysis. Parasit Vectors. 2017;10(Suppl. 2):494.

38. Lok JB, Knight DH, Nolan TJ, Grubbs ST, Cleale RM, Heaney K. Efficacy of an injectable, sustained-release formulation of moxidectin in preventing experimental heartworm infection in mongrel dogs challenged 12 months after administration. Vet Parasitol. 2005;128:129-35.

39. Prichard R, Menez C, Lespine A. Moxidectin and the avermectins: consanguinity but not identity. Int J Parasitol Drugs Drug Resist. 2012;2:134-53.

40. Center for Veterinary Medicine. Effectiveness of anthelmintics: general recommendations. VICH GL7 Technical Report. Rockville: Center for Veterinary Medicine; 2001

41. Center for Veterinary Medicine. Effectiveness of anthelmintics: specific recommendations for canine. VICH GL19 Technical Report. Rockville: Center for Veterinary Medicine; 2002.

42. Holmes RA, McCall JW, Prasse KW. Thiacetarsamide in dogs with Dirofilaria immitis: influence of decreased liver function on drug efficacy. Am J Vet Res. 1986;47:1341-4.

43. Wolstenholme AJ, Evans CC, Jimenez PD, Moorhead AR. The emergence of macrocyclic lactone resistance in the canine heartworm, Dirofilaria immitis. Parasitology. 2015;142:1249-59.

44. NexGard. Nexgard Spectra (EMEAN/C/003842/0000) EMA/695949/2014. Committee for Medicinal Products for Veterinary Use (CVMP) Assessment Report (EPAR). 2014. p. 21-2.

45. Vidyashankar AN, Jimenez Castro PD, Kaplan RM. A statistical approach for evaluating the effectiveness of heartworm preventive drugs: what does 100\% efficacy really mean? Parasit Vectors. 2017;10(Suppl. 2):516.

46. Grieve RB, Frank G, Stewart VA, Parsons JC, Abraham D, MacWilliams PS, et al. Effect of dosage and dose timing on heartworm (Dirofilaria immitis) chemoprophylaxis with milbemycin. In: Proceedings of heartworm symposium '89. Washington, DC: American Heartworm Society: 1989. p. $121-4$.

47. McTier TL, McCall JW, Jernigan AD, Rowan TG, Giles CJ, Bishop BF, et al. A novel avermectin for the prevention of heartworms in dogs and cats. In: Recent advances in heartworm disease: symposium '98. Batavia: American Heartworm Society; 1998. p. 187-92.

48. Paul AJ, Todd KS Jr, Sundberg JP, DiPietro JA, McCall JW. Efficacy of ivermectin against Dirofilaria immitis larvae in dogs 30 and 45 days after induced infection. Am J Vet Res. 1986;47:883-4.

49. Prichard RK, Geary TG. Perspectives on the utility of moxidectin for the control of parasitic nematodes in the face of developing anthelmintic resistance. Int J Parasitol Drugs Drug Resist. 2019;10:69-83.

50. Lallemand E, Lespine A, Alvinerie M, Bousquet-Melou A, Toutain PL. Estimation of absolute oral bioavailability of moxidectin in dogs using 
a semi-simultaneous method: influence of lipid co-administration. J Vet Pharm Ther. 2007;30:375-80.

51. Letendre L, Harriman J, Drag M, Mullins A, Malinski T, Rehbein S. The intravenous and oral pharmacokinetics of afoxolaner and milbemycin oxime when used as a combination chewable parasiticide for dogs. J Vet Pharm Ther. 2017:40:35-43.

52. Lo PK, Fink DW, Williams JB, Blodinger J. Pharmacokinetic studies of ivermectin: effects of formulation. Vet Res Commun. 1985;9:251-68.

53. Rock DW, DeLay RL, Gliddon MJ. Chemistry, pharmacology and safety of the macrocyclic lactones: moxidectin. In: Vercruysse J, Rew RS, editors. Macrocyclic lactones in antiparasitic therapy. Wallingford: CABI Publishing; 2002. p. 75-96.

54. Little SE, Hostetler JA, Thomas JE, Bailey KL, Barrett AW, Gruntmeir K, et al. Moxidectin steady state prior to inoculation protects cats from subsequent, repeated infection with Dirofilaria immitis. Parasit Vectors. 2015;8:107.

55. McCall JW, Varloud M, Hodgkins E, Mansour A, Dicosty U, McCall S, Carmichael J, Carson B, Carter J. Shifting the paradigm in Dirofilaria immitis prevention: blocking transmission from mosquitoes to dogs using repellents/insecticides and macrocyclic lactone prevention as part of a multimodal approach. Parasit Vectors. 2017:10(Suppl. 2):525.

\section{Publisher's Note}

Springer Nature remains neutral with regard to jurisdictional claims in published maps and institutional affiliations.
Ready to submit your research? Choose BMC and benefit from:

- fast, convenient online submission

- thorough peer review by experienced researchers in your field

- rapid publication on acceptance

- support for research data, including large and complex data types

- gold Open Access which fosters wider collaboration and increased citations

- maximum visibility for your research: over 100M website views per year

At BMC, research is always in progress.

Learn more biomedcentral.com/submissions 